\title{
Perioperative functional residual capacity
}

R.W.M. Wahba MB BCh MSc(McGill) FRCPC

The literature dealing with the magnitude, mechanism and effects of reduced FRC in the perioperative period is reviewed. During general anaesthesia $F R C$ is reduced by approximately $20 \%$. The reduction is greater in the obese and in patients with COPD. The most likely mechanism is the loss of inspiratory muscle tone of the muscles acting on the rib cage. Gas trapping is an additional mechanism. Lung compiance decreases and ainways resistance increases, in large part, due to decreased $F R C$. The larynx is displaced anteriorly and elongated, making laryngoscopy and infubation more difficult. The change in FRC creates or increases intrapulmonary shunt and areas of low ventilation to perfusion. This is due to the occurrence of compression atelectasis, and to regional changes in mechanics and ainvay closure which tend to reduce ventilation to dependent lung zones which are still well perfused. Abdominal and thoracic operations tend to increase shunting further. Large tidal volume but not PEEP will improve oxygenation, although both increase FRC. Both FRC and vital capacity are reduced following abdominal and thoracic surgery in a predictable pattern. The mechanism is the combined effect of incisional pain and reflex dysfunction of the diaphragm. Additional effects of thoracic surgery include pleural effusion, cooling of the phrenic nerve and mediastinal widening. Postoperative hypoxaemia is a function of reduced FRC and ainvay closure. There is no real difference among the various methods of active lung expansion in terms of the speed of restoration of lung function, or in preventing postoperative atelectasis/pneumonia. Epidural analgesia does not influence the rate of recovery of lung function, nor does it prevent atelectasis/pneumonia.

\section{Key words}

HYPOXIA: postoperative;

LUNG: functional residual capacity;

VENTILATION: anaesthetics, effects of; diaphragm;

oxygen tension, positive end-expiratory pressure, shunting.

From the department of Anacsthesia, Qucen Elizabeth Hospital and McGill University, Montreal, Quebec, Canada.

Accepted for publication 17th October, 1990.
La littérature concernant l'importance, le mécanisme et les effets de la réduction de la capacité résiduelle fonctionnelle en période périopératoire est revue. Durant l'anesthésie générale, la CRF est réduite de $20 \%$ approximativement. Cette réduction est plus grande chez les obèses et les patients ayam une maladie pulmonaire obstructive chronique. Le mécanisme le plus probable serait la perie du tonus musculaire inspiratoire des muscles agissant sur la cage thoracique. La captation des gaz serait un mécanisme additionnel. La compliance pulmonaire diminue et la résistance des voies aériennes augmente en grande partie à cause de la diminution de la CRF. Le larynx est déplacé antérieurement et ésiré rendant la laryngoscopie et rendant l'intubation plus difficiles. Les changements de la CRF créent et augmentent le shunt intrapulmonaire et les régions ayant un bon ratio de ventilation sur perfusion. Ceci est dû à la survenue de l'atélectasie par compression et à des changements régioncux mécaniques et la fermeture des voies aériennes qui tendent à réduire la ventilation aux zones pulmonaires dépendantes qui sont encore bien perfusées. Les opérations abdominales et thoraciques tendent à augmenter davantage le shunt. Le grand volume courant mais non la PEEP améliorerait l'oxygénation même s'il augmente la CRF. Tant la CRF que la capacité vitale sont réduites après chirurgie abdominale et thoracique d'une façon prévisible. Le mécanisme serait l'effet combiné de la douleur incisionnelle et la dysfonction réflexe du diaphragme. Les effets additionnels de la chirurgie thoracique incluem

\section{Outline}

I Basic physiology

- Forces acting on chest wall

- Determinants of FRC

- Relationship of FRC and lung mechanics

II FRC during anaesthesia

- Magnitude and features of reduced FRC

- Mechanism of reduced FRC

- Physiological consequences:

- altered mechanics

- enlarged $\mathrm{P}(\mathrm{A}-\mathrm{a}) \mathrm{O}_{2}$

III Postoperative pulmonary dysfunction

- Postoperative hypoxaemia

- Pulmonary defence mechanisms

- Breathing pattern and lung mechanics

- Mechanism of reduced FRC and VC

- Postoperative atelectasis and pneumonia

IV Summary and discussion 
A

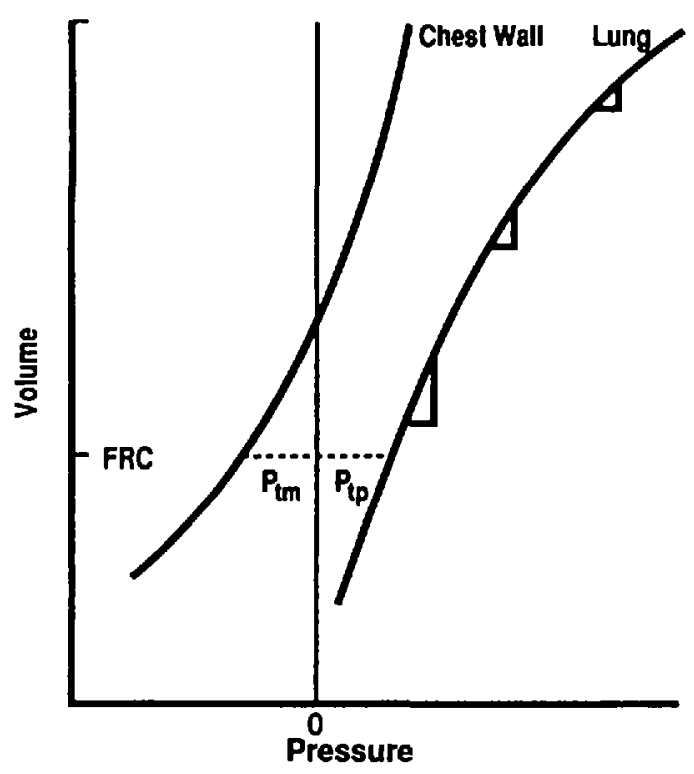

B

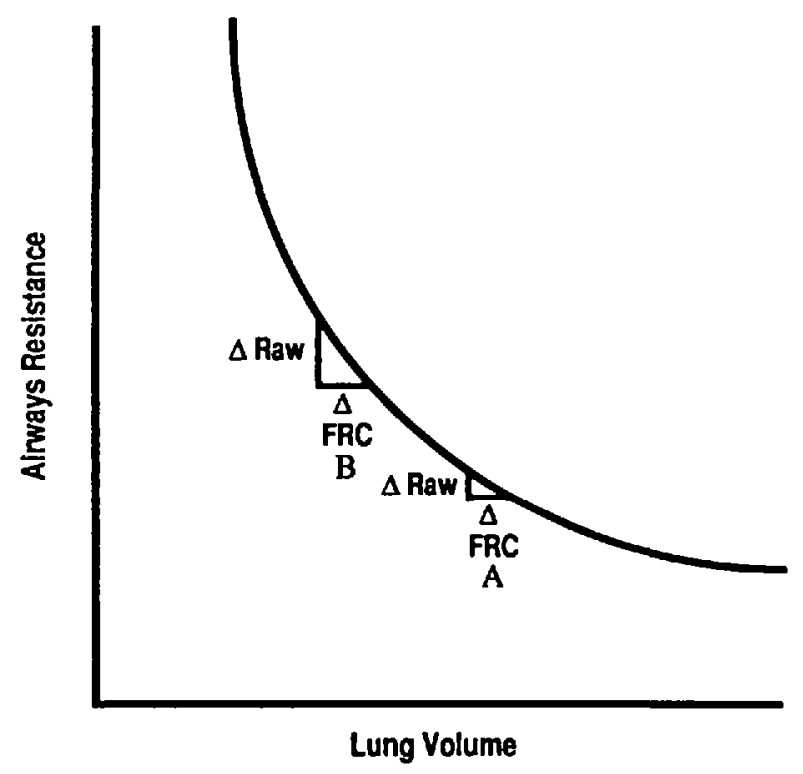

FIGURE 1 Functional residual capacity and pulmonary mechanics. Figure la, pressure:volume relationship (left). The pressure:volume relationship (compliances) of the chest wall and the lung are shown. Note that FRC is the lung volume at which PTP and PTM are equal but opposite. Any change in one pressure must entail an equal but opposite change in the other. The triangles subiending the lung compliance line illustrate the volume change for a given pressure change at different lung volumes. Figure lb. FRC and airways resistance (right). The relationship between lung volume and airways resistance (Raw) is a rectangular hyperbola. Note that for a given decrease in FRC, the increase in Raw is greater when the initial FRC is low (compare B with A).

l'épanchement pleural, le refroidissement du nerf phrénique et l'élargissement médiastinal. L'hypoxémie postopératoire est en fonction de la diminution de la CRF et de la fermeture des voies aériennes. Il n'y avait aucune différence réelle entre les différentes méthodes d'expansion active du poumon concernant la rapidité de la restauration de la fonction pulmonaire ou dans la prévention de l'atélectasie postopératoire-pneumonie. L'analgésie épidurale n'influence pas le taux de récupération de la fonction pulmonaire ni ne prévient l'atélectasie-pneumonie.

\section{Basic physiology}

The lungs and the chest wall are elastic but their natural shapes are different. Functional residual capacity (FRC) is the lung volume at which the balance between the natural tendency of the lung to retract and that of the rib cage to expand occurs. The FRC is also determined by the effect of gravity and will vary depending on position. At rest the end-expiratory pressure gradient across the lung (transpulmonary pressure, $\mathrm{Ptp}$ ) is numerically equal, but opposite in sign, to that across the chest wall (transmural pressure, Ptm) (Figure la). In the supine posture, in which FRC is reduced by $20-25 \%,{ }^{\prime}$ inspiratory tone is present in various muscles acting on the rib cage, particularly the scalene, stemomastoid, and parasternal intercostal muscles. It has been suggested that the diaphragm also has inspiratory tone. ${ }^{2}$ The purpose of the inspiratory tone is to maintain the abdominal contents within the abdomen ${ }^{2}$ and this tonic activity effectively increases FRC by about 0.4 to $0.8 \mathrm{~L}$. Indeed, partial curarization of supine subjects results in a decrease in FRC of about $0.8 \mathrm{~L}$, with a proportionate reduction of chest wall compliance. ${ }^{3}$

There are regional differences in all aspects of lung function due to surface forces which arise from the adaptation of structures of different natural shapes. These surface forces result in the creation of the vertical gradient of pleural surface pressure of approximately $0.25 \mathrm{~cm}$ $\mathrm{H}_{2} \mathrm{O} \cdot \mathrm{cm}^{-1}$. The magnitude of pleural pressure (Ppl) reflects the degree of regional expansion or retraction of the lung within the chest wall. The shape of the chest wall, consisting of the rib cage and the diaphragm, is determined by the structural rigidity of the rib cage and by the effects of gravity, particularly the gravitational pull on the abdominal contents and on the diaphragm. For these reasons, the uppermost lung units are the most distended units at resting lung volume and expand the least when large breaths are taken. They are in the sones where $\mathrm{Ppl}$ is most subatmospheric (negative). The opposite holds true 
for basal units, i.e., they are the smallest at rest but can expant the most. In these lung zones $\mathrm{Ppl}$ is the least negative, or even positive.

Airways resistance (Raw) increases as lung volume decreases. ${ }^{4}$ Thus, at or below FRC, there is a disproportionate increase in Raw with reductions in lung volume (Figure 1b). The largest contribution to total Raw comes from medium sized airways, while the terminal airways offer the least resistance due to their very large total cross-sectional area. Other factors which influence Raw are bronchomotor tone and the density and viscosity of inspired gases. Dynamic compression of airways occurs at mid- and low-lung volumes, limiting expiratory flow rate, and is exaggerated by increased Raw. Airways resistance increases by approximately $40 \%$ and compliance decreases by about $20-25 \%$ upon assuming the supine posture. ${ }^{5}$

Terminal airways, which are devoid of cartilagenous support, do not contribute significantly to overall Raw. But airways in dependent lung zones can close if there is loss of pulmonary elastic recoil or if Ppl becomes positive. This occurs with aging and obesity. ${ }^{6}$ The magnitude of airway closure is expressed as Closing Capacity (CC), which gains clinical importance if $\mathrm{CC}$ is greater than FRC.' The $\mathrm{CC}$ reflects complete and intermittent airway closure and is not changed in the supine position, while FRC is reduced. ${ }^{1}$ Airway closure increases the tendency to trap gas behind closed airways ${ }^{7}$ and the alveolar-arterial oxygen tension gradient $\left[\mathrm{P}(\mathrm{A}-\mathrm{a}) \mathrm{O}_{2}\right]$ is directly related to $\mathrm{CC} / \mathrm{FRC}$. $^{1}$

The distribution of inspired gases is not even throughout the lung in all body positions. The preferential distribution to dependant lung units is determined, for the same applied pressure, by regional compliance and airway resistance. ${ }^{8}$ The distribution of blood to the lungs is primarily determined by the effects of gravity. The interaction of the factors determining the spatial distribution of gases and blood results in the typical pattern of very high ventilation to perfusion $\dot{V}_{A} / \dot{Q}$ ratios in upper lung zones, with progressively lower ratios further down the lung.

The chest wall consists of two components: the rib cage and the abdomen:diaphragm. The two components act as a mechanical couple. In the supine position, the coupling is less effective and the mechanical advantage of the diaphragm is greatly reduced. For that reason strong phasic inspiratory intercostal activity is essential. This activity is also present in the parasternal region ${ }^{9}$ and probably in the diaphragm also ${ }^{2}$ and serves to reduce that loss. Tonic activity is essential to maintain optimal fibre length between phasic contractions. Intercostal muscles have a rich supply of muscle spindles in order to regulate

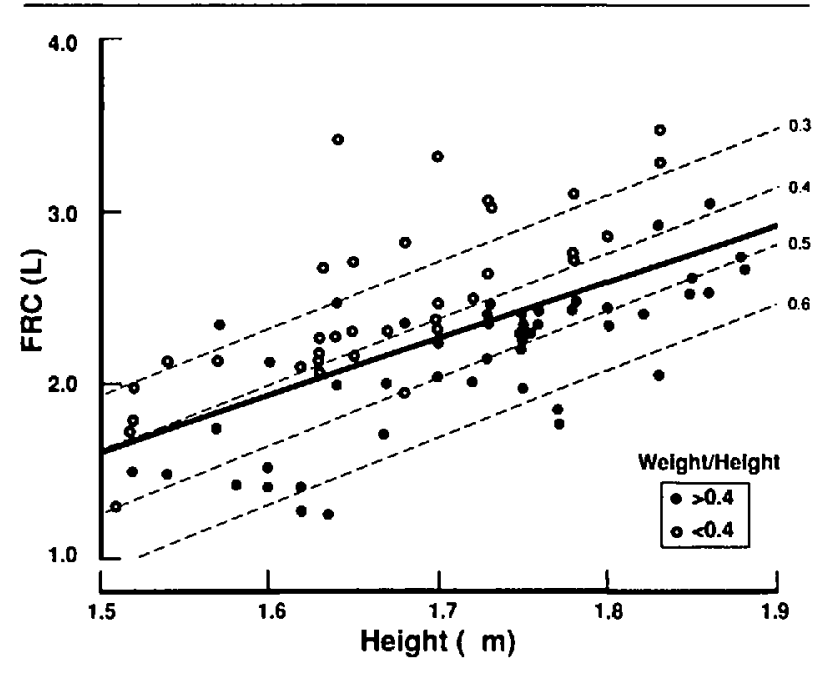

FIGURE 2 Influence of height and body build on FRC. FRC increases linearly with height as shown by the dark, continuous line. Relatively obese patients (weight $(\mathrm{kg}) /$ height $(\mathrm{cm})$ ratio $>0.4$ ) have lower FRCs than predicted by height alone. The light, interrupted lines give the expected FRC for a number of weight/height ratios. Data analyzed from published 1.7.11.12.93.94 and unpublished sources. The equations, calculated by regression analysis, are: (1) FRC $=(3.22 \times$ height $)-3.22 ; \mathrm{r}=0.62$. (2) $\mathrm{FRC}=(3.8 \times$ height $)-$ $(3.41 \times$ ratio $)-2.74 ; R=0.81$, standard error $=0.3$.

tonic and phasic activity. These spindles receive segmental and suprasegmental inputs and their adequate function requires spatial and temporal summation of these inputs. The physiology of the chest wall has been recently reviewed. ${ }^{10}$

Functional residual capacity, in the erect subject, is determined by height and is minimally influenced by age. In supine patients, FRC is mainly determined by height, but relative obesity has an adverse effect. Data from several sources are given in Figure 2.

\section{FRC during anaesthesia and surgery}

\section{A Magnitude and features of reduced FRC (Figure 3)} The FRC is reduced by approximately $20 \%(0.5$ to $0.7 \mathrm{~L})$ during anaesthesia induced with thiopentone and maintained by inhalational agents, iv narcotics or barbiturates $^{11-23,26-30}$ (Figure 3a), irrespective of whether breathing is controlled or spontaneous. There is no significant change on changing from spontaneous to controlled ventilation. An initial reduction of approximately $200 \mathrm{ml}$ occurs during the injection of thiopentone, coincident with the loss of consciousness. ${ }^{20}$ With ketamine, however, no change in FRC occurs in either adults, ${ }^{24}$ or children. ${ }^{25}$ Induction with methohexitone without subsequent tracheal intubation does not lead to a significant 


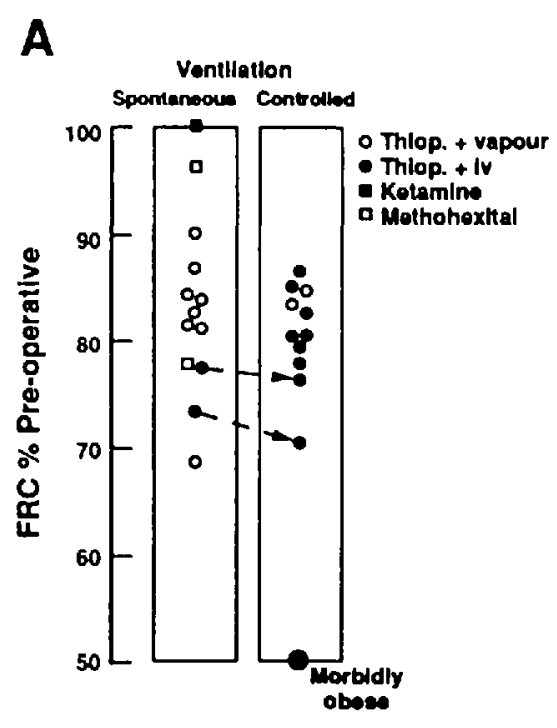

B

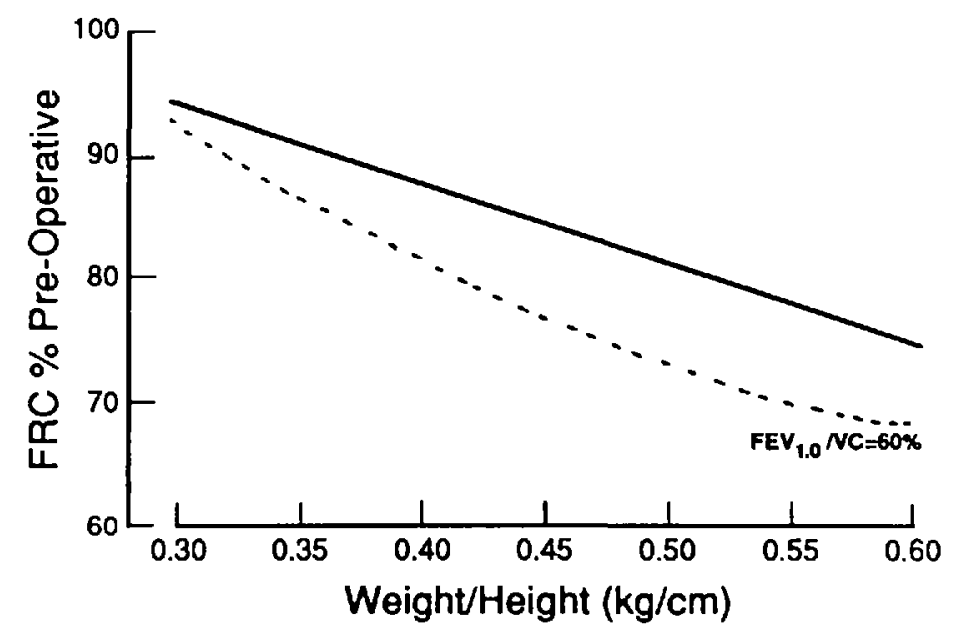

FIGURE 3 Intraoperative FRC. Figure 3a, mean intraoperative values of FRC (left). Mean intraoperative FRC values from 23 studies. In two, the values were reported during anaesthesia with spontaneous and with controlled ventilation (arrows). Figure 3b, relationship between change in FRC and weight:height ratios (right). The magnitude of change is primarily determined by body build, as given by the dark, solid line (calculated from references 11 and 12). Patients with severe COPD ${ }^{13.3}\left(\mathrm{FEV}_{1} / \mathrm{VC}<0.6\right)$ tend to have even lower FRCs. as shown by the interrupted line.

reduction, whereas FRC will be reduced by about $20 \%$ if methohexitone induction is followed by tracheal intubation, ${ }^{27}$ particularly if coughing occurs during intubation. ${ }^{27}$

The magnitude of reduction varies considerably and is primarily determined by body build. ${ }^{11-14}$ In the morbidly obese, FRC can be as low as $50 \%$ of awake values. ${ }^{26}$ Another major predictor of the magnitude of change is the severity of chronic airways disease expressed as $\mathrm{FEV}_{1} /$ FVC. ${ }^{13}$ Such patients have a lower FRC than predicted on the basis of body build (Figure 3b).

During anaesthesia for peripheral surgery, FRC is not influenced further by depth or duration of anaesthesia, manually delivered big breaths ("sighs") or by the inspired oxygen concentration. ${ }^{11,12}$

The reduction in FRC can be partially reversed by continuous positive airway pressure (CPAP) or by positive end-expiratory pressure (PEEP) $)^{32}$ and by a $30^{\circ}$ head-up tilt. ${ }^{33}$ Positioning anaesthetized normal subjects in the sitting position partially restores FRC. ${ }^{34}$

During abdominal or thoracic operations, FRC increases transiently when the cavity is opened. ${ }^{26,35}$ However, during the surgical procedure, FRC is decreased and returns to post-induction levels at the end of the procedure. Indeed, pulmonary gas exchange which is impaired following induction of anaesthesia, ${ }^{36-38}$ deteriorates during laparotomy ${ }^{38}$ but not during peripheral surgery. ${ }^{37}$ This difference probably is explained by the effect of surgical influences (packs, retractors, etc.) on FRC.

\section{B Mechanisms of reduced FRC}

Three possible mechanisms have been proposed to explain the reduction in FRC.

(a) Decreased chest wall recoil

The data strongly suggest that the most likely mechanism, coincident with loss of consciousness, is the immediate loss of inspiratory muscle tone, resulting in a loss of outward elastic recoil of the chest wall. The chest wall assumes a more expiratory position. Thus, Ptm changes, with a simultaneous change in Ptp in order to establish a new FRC (Figure 4). This proposed mechanism is supported by the following observations. Partial neuromuscular blockade in awake, supine subjects results in a markedly reduced FRC. ${ }^{3}$ Inspiratory muscle tone of the diaphragm, ${ }^{2}$ sternomastoid, scalene, and the parasternal intercostal muscles ${ }^{39}$ is lost during induction of anaesthesia. The change in the end-expiratory position of the rib cage and abdomen during the injection of thiopentone is consistent with a loss of lung volume and cephalad displacement of the diaphragm, ${ }^{40}$ secondary to the loss of inspiratory muscle tone. The cephalad displacement of the diaphragm, which particularly affects the dorsal position of that muscle, ${ }^{41}$ is variable ${ }^{42}$ and is in the order of $1.9 \pm 0.5 \mathrm{~cm} .{ }^{29}$

This change in position alters the diameters of the rib cage. There is an increase in the lateral and a decrease in the antero-posterior external diameters. ${ }^{44-46}$ The internal 


\section{A. Entire System}

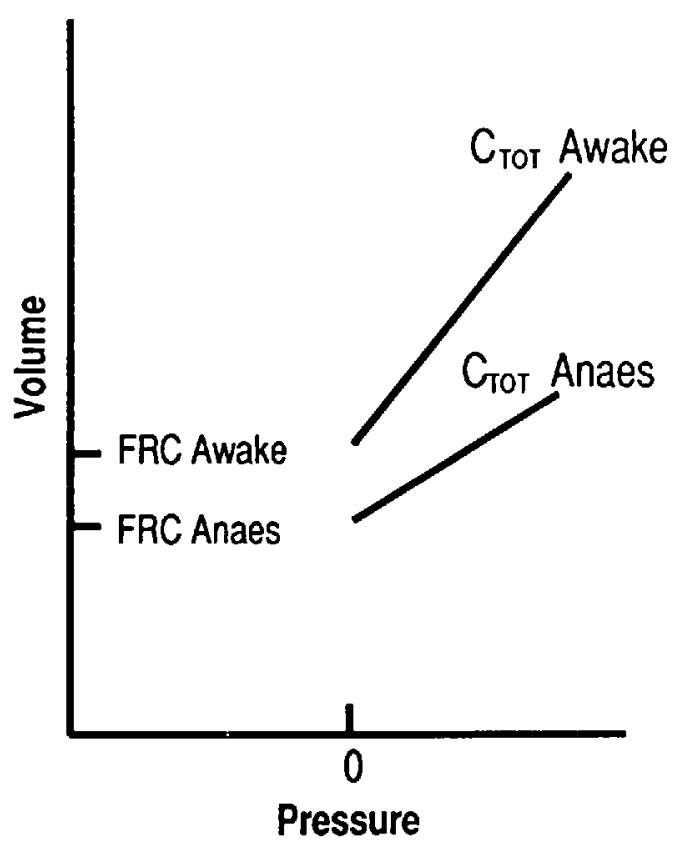

B. Lungs \& Chest Wall Separately

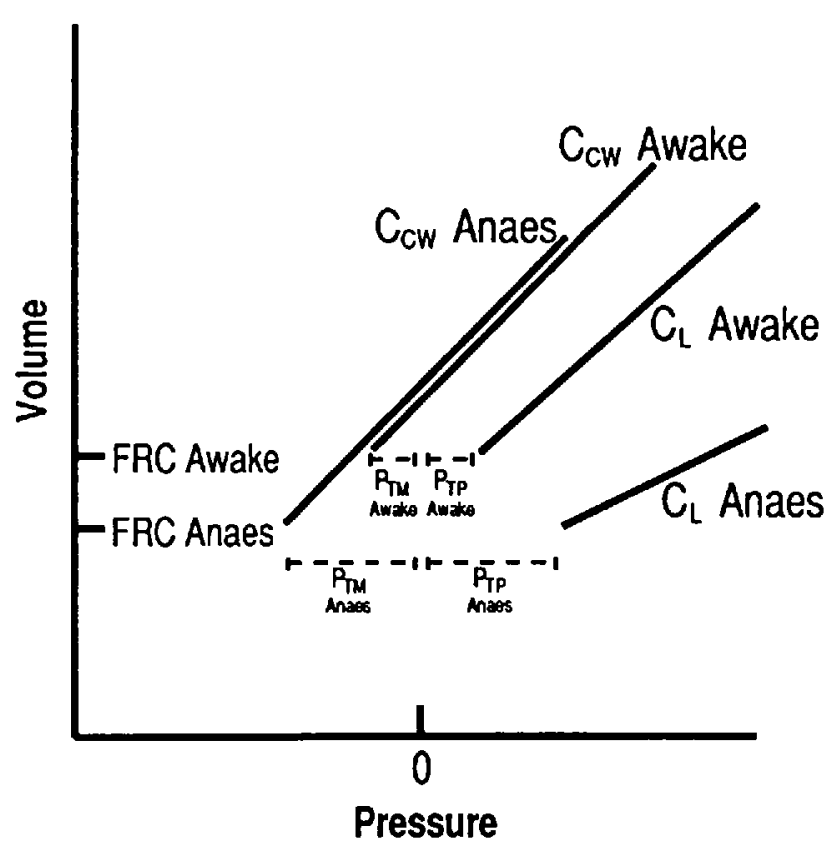

FIGURE 4 Proposed mechanism of reduced FRC. Figure 4a. changes in the compliance of the entire system (left). The figure shows the pressure:volume relationship of the lung and that of the chest wall together (total compliance CTor) in the awake state and during anaesthesia. Note the reduction in the intercept at 0 pressure (= reduced FRC) and the reduced slope ( = reduccd total compliance). Figure $4 \mathrm{~b}$. chest wall and lung compliances viewed separately (right). The figure shows the compliance of each separately in the two states. The chest wall takes a more expiratory position (closer to residual volume) without necessarily a change in the compliance slope (Ccw). However, transmural pressure (PTM) changes. Transpulmonary pressure (PTP) must, therefore, also change by an identical amount but in the opposite direction. These changes will mainly affect lower lung units (which are smaller at rest). Lung compliance (CL) will, as a result, decrease, as is evident from the change in slope.

diameters of the rib cage, ${ }^{29-39}$ particularly those of the upper portion, ${ }^{46}$ are reduced. The magnitude of reduction in internal diameters is directly proportional to the degree of obesity. ${ }^{47}$ The resulting change in cross-sectional area has been calculated to be equal to a loss in volume of 170 $\pm 140 \mathrm{ml}$ in one report ${ }^{45}$ and an average of $300 \mathrm{ml}$ in another. ${ }^{29}$

A reduction in tone of the diaphragm or of the muscles acting on the ventilatory pump will lead to a reduction in intragastric pressure (PGA) in lean patients. The average change in PGA immediately following induction of anaesthesia is $-40 \mathrm{~Pa} .{ }^{48}$ Obese patients, however, have relatively more inspiratory tone when awake. The loss of that tone during anaesthesia will increase abdominal and, hence, gastric pressure in obese patients. ${ }^{48}$

It is still not clear whether the changes in diaphragmatic postion are a direct effect of the anaesthetic state or a result of the effects of anaesthesia on the rib cage and abdominal muscles. The study of the physiology of the diaphragm, the rib cage and abdominal muscles and the interpretation of the results of such studies is difficult, ${ }^{49}$ particularly since the diaphragm may, in fact, be two muscles. ${ }^{50}$

(b) Increased lung recoil

An alternative explanation for the changes in FRC is that the change is due to an increase in recoil pressure of the lung. This is unlikely for two rcasons. These changes occur rapidly during induction of anaesthesia. Pulmonary recoil pressure measured during anaesthesia suggests that the increase in lung recoil is secondary to change in chest wall recoil. ${ }^{18}$ Also, the observations on PGa favour an effect on the chest wall. However, absorption atelectasis may occur when breathing oxygen-enriched gases at low lung, possibly causing further reductions. Increased lung recoil is, therefore, the result rather than the cause of decreased FRC.

(c) Increased abdominal pressure

This can displace the diaphragm in a cranial direction, reducing FRC, and is the result of either increased expiratory activity or increased blood volume. 
Increased abdominal pressure due to clinically evident expiratory muscle activity has been noted during halothane or narcotic anaesthesia, and could, theoretically, further reduce FRC. ${ }^{51.52}$ However, muscle paralysis, which abolishes this activity, does not restore FRC. ${ }^{11,18,20}$

An increase in abdominal blood volume, which can displace the diaphragm cranially, has been suggested as the cause of reduced FRC. ${ }^{53} \mathrm{~A}$ small $(150 \mathrm{ml})$ reduction in the volume of the four limbs occurs during thiopentoneneuroleptanaesthesia but not during inhalational or regional anaesthesia. This volume, presumably blood, may be added to the central circulation. ${ }^{54}$ Subsequently, the same investigators noted a $300 \mathrm{ml}$ reduction in thoracic blood volume during halothane anaesthesia, ${ }^{29}$ in contrast to an increase (about $250 \mathrm{ml}$ ) in thoracic blood volume during fentanyl anaesthesia. ${ }^{46}$ The preliminary results of compartmental blood volume determinations using radio isotopes during halothane anaesthesia indicate that no change in thoracic blood volume occurs. ${ }^{55}$

In conclusion, FRC is reduced principally and primarily by reduced inspiratory muscle tone. An additional mechanism is gas trapping behind closed airways. The FRC will be significantly reduced following tracheal intubation, especially if the latter causes protracted coughing. ${ }^{37}$ This suggests that tracheal intubation, which causes a reflex increase in airways resistance in spite of very thorough topical anaesthesia, ${ }^{56}$ may further reduce FRC by trapping gas behind closed airways. There is clear evidence that a variable amount of gas is trapped. ${ }^{12,44}$ The volume of trapped gas ranges from 2 to $5.8 \%$ of total lung capacity $(120-350 \mathrm{ml}) .^{12}$

\section{$C$ Consequences of reduced $F R C$}

\section{INTRAOPERATIVE PULMONARY MECHANICS}

The decrease in chest wall elastic recoil results in an increase of lung recoil pressure (i.e., decreased compliance) and the establishment of the new FRC. ${ }^{18,21}$ During anaesthesia, lung compliance is reduced by approximately $20 \%$ and has many of the features of reduced FRC. Thus, the reduction in compliance is more in obese patients, ${ }^{31.57}$ and is directly related to the magnitude of reduced FRC. ${ }^{18}$ Compliance is not affected by large breaths, ${ }^{18}$ time, ${ }^{58}$ or by muscle relaxants. ${ }^{18,59}$ Patients with reduced vital capacity before surgery will have lower compliances than normal patients during anaesthesia. ${ }^{59,60}$ Although the principal cause of decreased compliance is the decreased chest wall recoil pressure, absorption atelectasis and altered surfactant activity during anaesthesia may occur.

Airways resistance is inversely related to lung volume and one should expect, therefore, that Raw should be increased during anaesthesia. ${ }^{61}$ Mcasured values reflect the balance of the influence of reduced lung volume, the tracheal tube resistance ${ }^{59.60}$ and that due to reflex peripheral airway constriction ${ }^{56}$ on the one hand, and the dose-related bronchodilatory effect of the inhalational agent on the other. ${ }^{62}$ Indeed, the flow resistance of the tracheobronchial tree alone in young healthy patients with normal body build during anaesthesia is the same as that in awake subjects. ${ }^{59,60}$ But that does not hold true in obese patients and those with low $\mathrm{FEV}_{1} / \mathrm{VC}$ ratios. Expired minute volume during clinical halothane ${ }^{63}$ and enflurane ${ }^{64}$ anaesthesia with spontaneous ventilation is less in patients with low FEV $\mathrm{F}_{1}$. This is believed to be due to the higher airways resistance in patients with low $\mathrm{FEV}_{1}$. Patients with chronic airways disease have a lesser response to a $\mathrm{CO}_{2}$ challenge during anaesthesia than normal, presumably due to the expected reduction in FRC and increased airways resistance. ${ }^{63.64}$ Thus, the breathing pattern of patients with low $\mathrm{FEV} / \mathrm{VC}$ ratios, and the obese, is "loaded."

The changes in FRC and lung mechanics are regionally distributed and will be more pronounced in basal lung units. Furthermore, the effects of regional changes in FRC will be greater than can be estimated from a knowledge of overall FRC. ${ }^{8.41}$

The position and shape of the larynx change after induction of anaesthesia. ${ }^{65}$ The larynx is moved anteriorly and is elongated due to the anterior displacement of the epiglottis and hyoid bone with longitudinal stretching of the larynx. These changes are believed to be caused by the loss of tone of upper airway muscles and by the changes in lung elasticity. These changes, which coincide with and have the same mechanism as that of reduced FRC, may make laryngoscopy difficult. The length of the trachea is increased, presumably due to the changes in pulmonary elasticity. These changes, particularly in the obese, may make intubation very difficult or impossible.

\section{INTRAOPERATIVE HYPOXAEMIA AND FRC}

Arterial oxygenation during general anaesthesia is usually impaired. A major mechanism is the creation or increase in areas with zero or low ventilation:perfusion $\left(\dot{V}_{A} / \dot{Q}\right)$. Historically, the first suggestion that these changes in arterial oxygenation were due to reduced FRC was made in 1959. ${ }^{66}$ This proposal has been supported by the relationship between the magnitude of change in FRC and arterial hypoxaemia during general anaesthesia with both spontaneous and controlled ventilation. ${ }^{13,15,27}$ The extent of change in shunt and low $\dot{V}_{\mathbf{A}} / \dot{Q}$ condition can be seen by examining Figure 5, which summarizes three reports which differentiate shunt from low $\dot{V}_{A} / \dot{Q} \cdot{ }^{36-38}$ In all patients, whether healthy or with COPD, both shunt and low $\dot{V}_{A} / \dot{Q}$ increase following induction of anaesthesia. But the relative increase in normals (about 300\%) is 


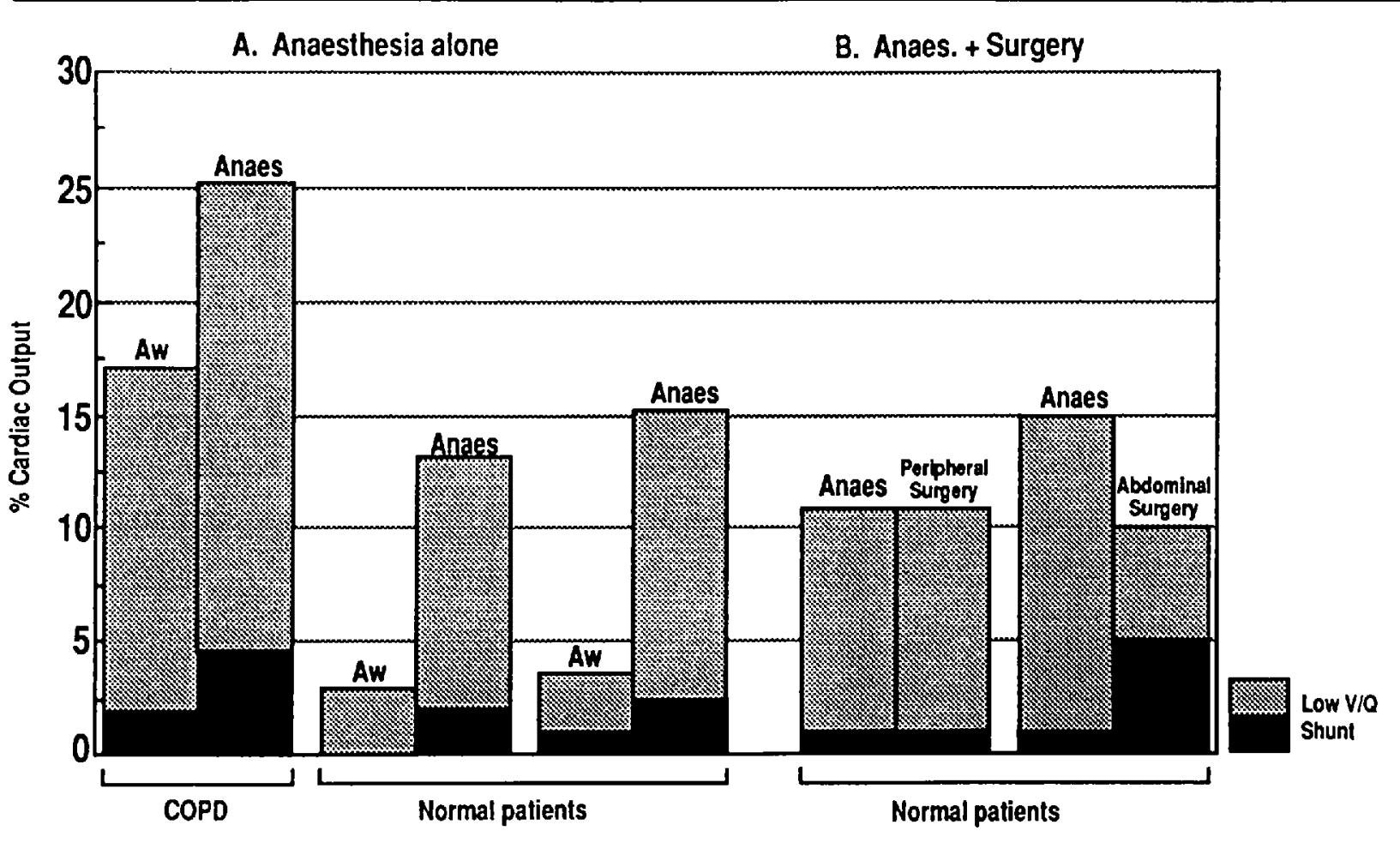

FIGURE 5 Shunt and low $\dot{V}_{A} / Q \dot{Q}$ during anaesthesia and operation. Figurc 5a, shunt and low $\dot{V}_{A} / Q$ during anacsthesia alone (left). The values of shunt and low $\dot{V}_{\mathrm{A}} / \mathrm{Q}$ (expressed as \% cardiac output) awake (aw) and during anaesthesia (anaes) alone from three sources ${ }^{36-38}$ are shown. In patients with COPD, the sum of shunt and low $\dot{V}_{A} / \dot{Q}$ during anaesthesia is greater than that in normal patients. However, the percentage increase is greater in normal patients. Figure $5 \mathrm{~b}$, shunt and low $\dot{V}_{\mathrm{A}} / \mathrm{Q}$ during operations (right). Shunt and low $\dot{V}_{\mathrm{A}} / \mathrm{Q}$ do not change during peripheral arterial reconstructive operations, ${ }^{36}$ in contrast with an increased shunt and decreased low $\dot{V}_{A} / \dot{Q}$ during intraabdominal procedures. ${ }^{38}$

markedly larger than the increase (about $45-50 \%$ ) noted in patients with COPD. The mechanism is believed to be the combined effects of atelectasis, airway closure and pulmonary mechanics affecting the matching of ventilation to perfusion. Each of these will be examined separately. The influence of other determinants of enlarged $\mathrm{P}(\mathrm{A}-\mathrm{a}) \mathrm{O}_{2}$ (Table I) will not be discussed.

\section{(a) Atelectasis}

The proposal that both lung compliance and $\mathrm{P}(\mathrm{A}-\mathrm{a}) \mathrm{O}_{2}$ are progressively reduced during anaesthesia, secondary to sub-radiological microatelectasis ${ }^{67}$ was seriously challenged by many investigators ${ }^{68}$ and it is now accepted that the initial reduction in both measurements remains constant during anaesthesia. It is possible that radiologically undetectable atelectasis might occur. This was extensive-

TABLE I Components of alveolar-arterial $\mathrm{PO}_{2}$ difference

\section{Impaired diffusion}

Increased shunt

Increased ventilation:perfusion scatter

Decreased mixed venous oxygen content

Shift of oxyhaemoglobin dissociation curve ly investigated by serial computerized tomographic (CT) scanning of the lungs. Small areas of increased density in the most caudal, dependent portions only of the lung appear within five minutes of the induction of anaesthesia. The extent is not influenced by either time or $\mathrm{FIO}_{2}$ but can be reduced by PEEP. ${ }^{69}$ Further investigation showed that these areas are due to the anaesthetic state because they occur with both inhalational ${ }^{69-71}$ and narcotic anaesthesia. ${ }^{71}$ Also, they occur with spontaneous and with controlled ventilation. ${ }^{71}$ The densities persist in $90 \%$ of patients for one hour after anaesthesia and in 50\% for $24 \mathrm{hr}{ }^{71}$ The densities were subsequently shown to be atelectatic areas rather than a result of fluid accumulation. ${ }^{72}$ They are presumably caused by the changes in the chest wall that occur during induction of anaesthesia and can, therefore, be termed "compression atelectasis" because they occur in lung zones in direct contact with the areas of the chest wall which undergo changes during induction. Since their perfusion persists, ${ }^{72}$ they increase Q́s/Q́T. Although relatively small, the extent has significant correlations with the magnitude of intraoperative shunt $(\dot{\mathrm{Q}} \mathrm{s} / \mathrm{Q} \mathrm{T})$ and the impairment of $\mathrm{P}(\mathrm{A}-\mathrm{a}) \mathrm{O}_{2} \cdot{ }^{73}$ The application of PEEP does decrease the extent of the atelectasis, but oxygenation is not improved. ${ }^{69,74}$ 
Atelectatic areas do not appear under two conditions: during ketamine anaesthesia with spontaneous breathing $^{75}$ and in patients with severe COPD. ${ }^{76}$ The FRC is not changed during ketamine anaesthesia ${ }^{24}$ with spontaneous breathing but is reduced during ketamine anaesthesia with controlled ventilation following pancuronium neuromuscular blockade. ${ }^{75}$ In this instance, shunt is related to the extent of the atelectasis (Table II). It is probable that pancuronium abolishes inspiratory tone, leading to FRC reduction and atelectasis. Functional residual capacity is markedly reduced in patients with severe COPD, ${ }^{13}$ in whom extensive shunting and $\dot{\mathrm{V}}_{\mathrm{A}} / \mathrm{Q}$ mismatching during nitrous oxide:oxygen anaesthesia occur. ${ }^{36}$ However, atelectatic areas do not appear in the majority (80\%) of COPD patients during enflurane:Oxygen-enriched air anaesthesia, ${ }^{76}$ nor is there an increased shunt or a change in intrathoracic volume (as assessed by $C T$ scanning), suggesting no change in FRC. ${ }^{76}$ The enlarged $P(A-a) O_{2}$ is mainly due to very low $\dot{V}_{A} / \dot{Q}$ without any significant change with time. These observations suggest two things: first, severe COPD protects the lung from developing atelectasis during anaesthesia, if nitrous oxide is avoided; secondly, the expected reduction of FRC in patients with

TABLE II Relationship of atclectatic areas to shunt $/ \mathrm{PaO}_{2}$ during anaesthesia

\begin{tabular}{lll}
\hline Ref. & Equation & $(r)$ \\
\hline 73 & Shunt $=1.23+[2.17 \times$ area $]$ & $(0.93)$ \\
& $\mathrm{PaO}_{2}=18.0+[5.13 \times 1 /$ area $]$ & $(0.99)$ \\
74 & $\mathrm{Shunt}=0.88+[1.81 \times$ area $]$ & $(0.84)$ \\
& $\mathrm{PaO}_{2}=131.0+[37.8 \times[/$ area $]$ & $(0.79)$ \\
75 & $\mathrm{Shunt}^{2} 1.04+[1.41 \times$ arca $]$ & $(0.81)$ \\
\hline
\end{tabular}

COPD is, to a marked degree, due to gas trapping behind closed airways, since the dimensions of the thoracic cage do not change.

Age, sex, and smoking history of individual patients are not determinants of the surface areas of the atelectatic zones. The surface areas, however, are determined by the degree of obesity and by the general shape of the thorax, expressed as the ratio of the square root of the transverse thoracic area/lung height. ${ }^{77}$ This mathematical expression is based on the fact that the general shape of the chest is approximately a truncated cone.

\section{(b) Airway closure}

Airway closure becomes clinically important when CC exceeds FRC. The earliest studies of airway closure in surgical patients examined the influence of surgical position. Whenever adopting the supine position placed $\mathrm{CC}$ above FRC [CC/FRC $>1.0]$, venous admixture increases and gas trapping occurs. ${ }^{1.7}$ Subsequent studies found that when intraoperative FRC or FRC plus tidal volume were less than preoperative $C C$, significant gas trapping and enlargement of $\mathrm{P}(\mathrm{A}-\mathrm{a}) \mathrm{O}_{2}$ occurred. ${ }^{12,16}$ The influence of $\mathrm{CC}$ on gas trapping and oxygenation as reported in these four studies is more clearly defined by classifying patients on the basis of the numeric value of CC/FRC (Table III). If control CC/FRC was less than 1.00 , then the percentage increase in gas trapping ${ }^{7.12}$ was minimal and $\mathrm{P}(\mathrm{A}-\mathrm{a}) \mathrm{O}_{2}$ was decreased.' Also reducing tidal volume from 10 to $5 \mathrm{ml} \cdot \mathrm{kg}^{-1}$ did not markedly influence $\mathrm{P}(\mathrm{A}-\mathrm{a}) \mathrm{O}_{2}{ }^{16}$ If control $\mathrm{CC} / \mathrm{FRC}$ was 1.0 to $1.25, \mathrm{P}(\mathrm{A}-\mathrm{a}) \mathrm{O}_{2}$ and gas trapping were markedly increased in the supine position ${ }^{1,7}$ and during anaesthesia. ${ }^{12}$ In this class of patients, reducing tidal volume from 10 to 5 $\mathrm{ml} \cdot \mathrm{kg}^{-1}$ significantly increased $\mathrm{P}(\mathrm{A}-\mathrm{a}) \mathrm{O}_{2}$. If $\mathrm{CC} / \mathrm{FRC}$

TABLE III Influence of airway closure on gas exchange

\begin{tabular}{|c|c|c|c|}
\hline $\begin{array}{l}\text { Experimental design, } \\
\text { measurement, and } \\
\text { reference (\#) }\end{array}$ & $\begin{array}{l}\text { Group } A \\
C C / F R C<1.0\end{array}$ & $\begin{array}{l}\text { Group B } \\
\text { CCIFRC }<1.0\end{array}$ & $\begin{array}{l}\text { Group } C \\
\text { CCIFRC }<1.25\end{array}$ \\
\hline \multicolumn{4}{|l|}{ A Posture* } \\
\hline (1) $\mathrm{P}\left(\mathrm{A}-\mathrm{aO} \mathrm{O}_{2}\right):$ & Decrease & Increase & No change \\
\hline (7) Gas trapping & Small increase & Increase: $\times 2.49$ & Increase: $\times 0.89$ \\
\hline \multicolumn{4}{|l|}{ B Anaesthesia } \\
\hline \multirow[t]{2}{*}{ (12) Gas trapping } & Awake $0.07 \%$ TLC & Awake $0.12 \%$ TLC & Awake $1.22 \%$ TLC \\
\hline & Anaes. $0.67 \%$ TLC & $\begin{array}{l}\text { Anacs. } 1.45 \% \text { TLC } \\
(\times 11 \text { increasc })\end{array}$ & $\begin{array}{l}\text { Anaes. } 3.93 \% \text { TLC } \\
(\times 2.22 \text { increasc })\end{array}$ \\
\hline \multicolumn{4}{|l|}{ (I6) $\quad \mathrm{P}\left(\mathrm{A}-\mathrm{aO}_{2}\right)$} \\
\hline VI $5 \mathrm{ml} \cdot \mathrm{kg}^{-1}$ & $<150 \mathrm{mmHg}$ & $239 \mathrm{mmHg}$ & $241 \mathrm{mmHg}$ \\
\hline VT $10 \mathrm{ml} \cdot \mathrm{kg}^{-1}$ & $<150 \mathrm{mmHg}$ & $188 \mathrm{mmHg}$ & $276 \mathrm{mmHg}$ \\
\hline
\end{tabular}

* Seated to supine.

Regression analysis: (a) Intraoperative trapped gas $=0.2 \mathrm{e}^{3.7 \mathrm{CC} / \mathrm{FRC}} ;$ (b) Intraoperative $\mathrm{P}\left(\mathrm{A}-\mathrm{aO}_{2}\right)=35.38+$ $137.43 \mathrm{CC} / \mathrm{FRC}$ (calculated from group means). 

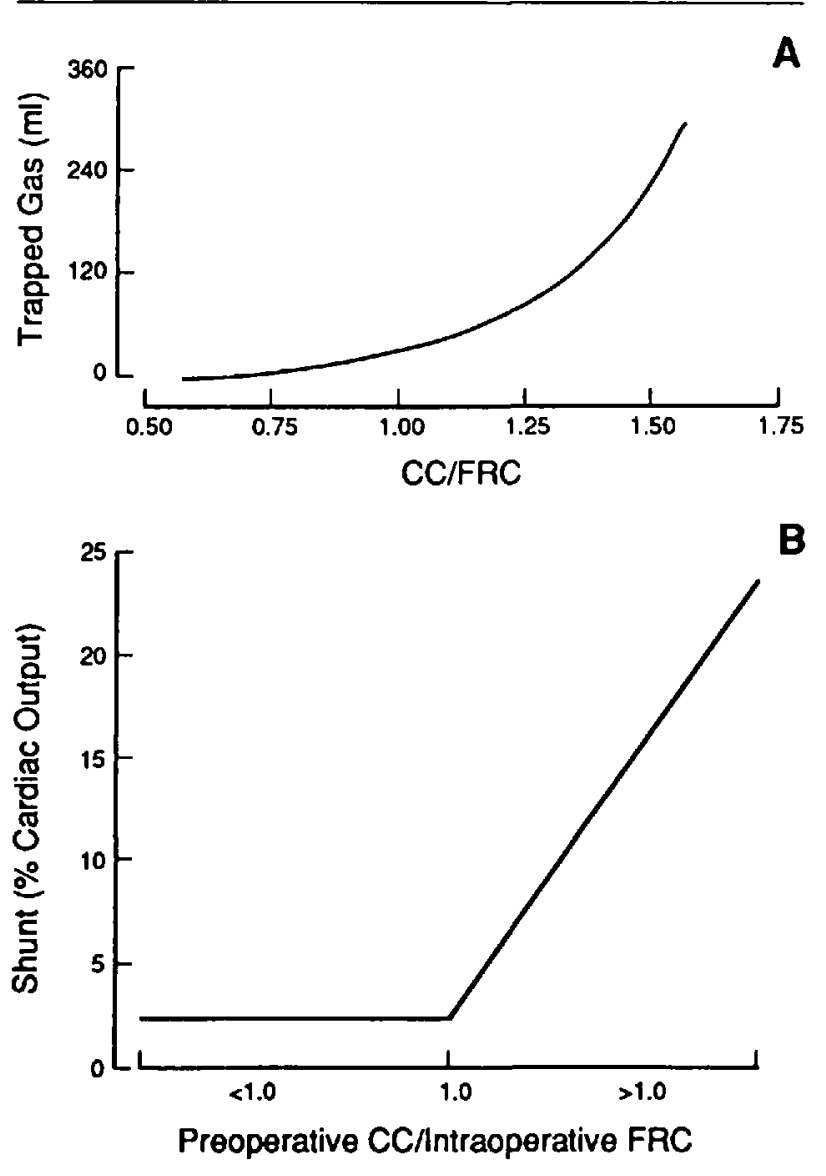

FIGURE 6 Influence of airway closure on intraoperative gas trapping and shunt. Figure $6 \mathrm{a}$, relationship between $\mathrm{CC} / \mathrm{FRC}$ and trapped gas volume (upper panel). Gas trapping during anaesthesia increases exponentially as preoperative CC/intraoperative FRC increases. Data calculated from reference 12. Figure 6b, relationship between $\mathrm{CC} / \mathrm{FRC}$ and intraoperative shunt (lower panel). Introperative shunt increases markedly as intraoperative FRC becomes progressively less than preoperative CC. The slope is steeper in heavy smokers and in obese patients. Data from reference 36.

$>1.25$, posture, anaesthesia and tidal volume did not have a marked influence on gas trapping or $P(A-a) O_{2}$. It is as if maximally compromised patients have a compensatory mechanism, such as collateral ventilation or facilitated recruitment. A definite compensatory mechanism has not been demonstrated. Patients with severe COPD have extensive airway closure. It was noted above that such patients did not develop atelectasis if nitrous oxide was not used. A number of studies reported that intraoperative $\mathrm{P}(\mathrm{A}-\mathrm{a}) \mathrm{O}_{2}$ had a statistically significant correlation with $\mathrm{CC} / \mathrm{FRC}$ or $\mathrm{CC}-\mathrm{FRC},{ }^{21,30,78}$ strongly suggesting a cause:effect relationship. But the coefficients of correlation reported in these references $(0.46,0.53$, and 0.52 respectively) indicated that other factors also influenced intraoperative $\mathrm{P}(\mathrm{A}-\mathrm{a}) \mathrm{O}_{2}$ and that the numeric value of the latter could not be adequately predicted from a knowledge of $\mathrm{CC} / \mathrm{FRC}$. Arterial $\mathrm{PO}_{2}$ during anaesthesia with spontaneous ventilation in a number of studies was found to decrease with age, ${ }^{6}$ which increases airway closure.

The lung volume during anaesthesia at which shunting begins is related to preoperative $\mathrm{CC}$. True shunting occurs when intraoperative FRC equals preoperative $\mathrm{CC}$, or preoperative $\mathrm{CC}$ /intraoperative FRC equals $1.0^{28}$ (Figure 6). The rate of increased $\dot{Q} s / \dot{Q} T$ with progressively smaller intraoperative FRC's is significantly more in the obese and in heavy smokers. ${ }^{28}$ These observations support the hypothesis that a major cause of enlarged intraoperative $\mathrm{P}(\mathrm{A}-\mathrm{a}) \mathrm{O}_{2}$ is regional lung volume reduction associated with an FRC decrease to less than $\mathrm{CC}$. Gas trapping increases exponentially with increasing CC/FRC (Figure 6). Breathing at lung volumes between $\mathrm{CC}$ and residual volume (RV) increases airway closure and its effects on gas exchange, ${ }^{79}$ particularly with oxygenenriched gases. ${ }^{80}$

The application of positive end expiratory pressure (PEEP) to increase FRC and to reduce $\mathrm{P}(\mathrm{A}-\mathrm{a}) \mathrm{O}_{2}$ during anaesthesia has limited benefit, ${ }^{30,32.81}$ although PEEP increases FRC and reduces atelectasis. ${ }^{30,70.74}$ That is because the pressure applied will preferentially affect upper lung zones, whereas airway closure and reduced FRC predominantly affect dependent lung zones. Also, since Ppl, and, hence, transpulmonary pressure (Ptp) is greater in dependent lung zones, the critical opening pressure is approximately $0.6 \mathrm{kPa} .{ }^{81} \mathrm{PEEP}$ may also have deleterious effects on cardiac output and pulmonary perfusion, causing further $\dot{\mathrm{V}}_{\mathrm{A}} / \dot{\mathrm{Q}}$ mismatching. ${ }^{81}$ The alternative to PEEP is large $\left(10-12 \mathrm{ml} \cdot \mathrm{kg}^{-1}\right)$ tidal volumes which have been shown to counteract the effects of airway closure ${ }^{16}$ and to be as effective as PEEP $^{82}$ in restoring FRC.

It is not clear whether $\mathrm{CC}$ is changed during anaesthesia. The results of measurements of $\mathrm{CC}$ by the foreign gas technique (which is the appropriate method) are not in agreement. One study reports that $\mathrm{CC}$ and FRC are reduced to almost the same degree, ${ }^{23}$ while another found no change in $\mathrm{CC}$ during anaesthesia, ${ }^{22}$ confirming the same authors' previous results ${ }^{21.30}$ using the resident gas method. The reason for the difference in results is not clear.

\section{(c) Low $\dot{V}_{A} / \dot{Q}$ zones}

This comprises lung zones without compression atelectasis or complete airway closure but which have inordinately low ventilation relative to perfusion. The distribution of gases is primarily determined by the interaction of the admitting forces (i.e., chest wall expansion) and regional impedance (to all practical purposes, airways resistance 


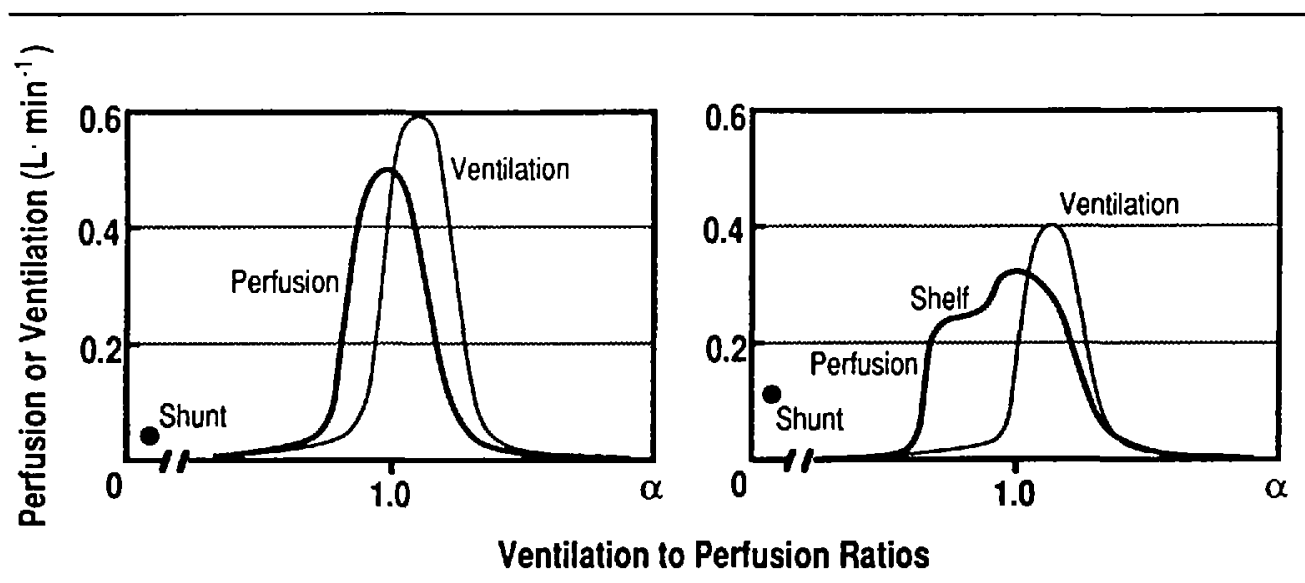

FIGURE 7 Relationship between regional $\dot{V}_{\mathrm{A}} / \dot{Q}$ and regional perfusion. The contour of the line describing the distribution of regional perfusion to the entire spectrum of $\dot{V}_{A} / Q$ ratios in the absence of airway closure is smooth and bell shaped, as shown in the left-hand panel. The curve becomes "bimodal" with the appearance of a shelf whenever there is an abrupt reduction in regional ventilation (right-hand panel)

and compliance). Regional impedance is a function of regional FRC. It is impossible to quantify the local effects of regional reductions in FRC in creating lung zones with very low $\dot{V}_{A} / \dot{Q}$, but such an effect can be graphically visualized. The graphic representation of virtually continuous $\dot{V}_{\mathrm{A}} / \dot{Q}$ ratios versus either perfusion or ventilation is normally bell-shaped as shown in Figure 7a. Any abrupt change in the distribution of ventilation (airway closure) will change the shape of the perfusion curve to a bimodal pattern with the appearance of a shelf (Figure 7b).

The FRC, shunt and low $\dot{V}_{\mathrm{A}} / \dot{\mathrm{Q}}$ areas do not change to any marked degree upon changing from spontaneous to controlled ventilation. ${ }^{74,81}$ Immediately following laparotomy $^{26}$ or thoracotomy, ${ }^{35}$ but before actual surgery, FRC increases. In sharp contrast, FRC does not change during peripheral surgery. " During abdominal surgery, shunt increases while low $\dot{V}_{A} / \dot{Q}$ decreases. This reflects the effects of surgical manipulations (packs, retractors, etc.). During thoracotomy, coincident with reduced FRC, $\mathrm{PaO}_{2}$ decreases ${ }^{35}$ and the general shape of expired $\mathrm{CO}_{2}$ curves undergoes changes compatible with increased impedance and reduced FRC. ${ }^{83}$

\section{Summary}

Recent technological advances have shown that the intraoperative increase of $\mathrm{P}(\mathrm{A}-\mathrm{a}) \mathrm{O}_{2}$ is due to the creation or increase in shunt in areas of low $\dot{V}_{A} / \dot{Q}$. These are due to reduced FRC. Arterial $\mathrm{PO}_{2}$ can be increased by large tidal volumes but not by PEEP. Intraoperative shunt is greater in patients with pre-existing low $\mathrm{PaO}_{2}$. But the percentage increase is larger in healthy subjects. Intraabdominal and intrathoracic operations increase shunting, presumably by reducing FRC further.

\section{Postoperative pulmonary dysfunction and FRC}

Postoperative hypoxaemia, atelectasis and pneumonia are of particular concern due to their contribution to postoperative morbidity and mortality after major surgery. Reduced FRC is important in the production of all three. Postoperative recovery of lung function has been extensively reviewed ${ }^{84}$ and the following section will review more recently published information.

\section{A Postoperative hypoxaemia}

The inverse relationship between $\mathrm{PaO}_{2}$ and age is markedly accentuated following surgery. ${ }^{85}$ Postoperative hypoxaemia increases in the obese ${ }^{86}$ The pattern of "guarded" breathing with shallow, rapid breaths, which promotes atelectasis, leads to inefficient gas exchange. Postoperative hypoxaemia is an important result of airway closure ${ }^{87}$ The $\mathrm{CC}$ is reduced after surgery but proportionately less than the FRC, augmenting the effects of airway closure ${ }^{87}$ There is a very significant relationship between $\mathrm{CC} / \mathrm{FRC}$ and postoperative $\mathrm{PaO}_{2}{ }^{87}$ Factors other than $\dot{V}_{A} / \dot{Q}$ mismatching which cause postoperative hypoxaemia are reduced mixed venous oxygen content and increased oxygen consumption.

Maximum reduction in $\mathrm{PaO}_{2}$ occurs during the first 48-72 hr, during which unexpected myocardial ischaemia may occur, suggesting a causal relationship. Arterial desaturation occurs normally during natural sleep. The frequency and severity of desaturation increase following surgery ${ }^{88}$ and explain the disorientation frequently noted, particularly in the aged. Narcotic analgesics increase the degree of desaturation, which are possibly due to further, transient reductions in the FRC. The degree of postoperative hypoxaemia has been used as 
TABLE IV Factors promoting postoperative retention of secretions

Reduced small airway calibre

Decreased alveolar size and stability

Altered breathing pattern and loss of sigh

Increased and/or diy secretions

Decreased effective coughing

Decreased/altered Inuco-ciliary activity

a numeric criterion in diagnosing postoperative pneumonia.

\section{B Pulmonary defense mechanisms}

The pathogenesis of atelectasis and pneumonia includes a number of factors which promote the retention of secretions (Table IV). Two particular aspects of pulmonary defense mechanisms, coughing and removal of particulate matter, are adversely affected by the changes in lung mechanics and breathing pattern. Vital capacity, which is critical for effective coughing, is reduced very shortly after surgery by as much as 40 or $50 \%$ of preoperative values. ${ }^{84}$ Gradual restoration over the next few days is usual. Removal of secretions and particulate matter also becomes inefficient following surgery, probably as a result of the restrictive breathing pattern. Radio-opaque material inhaled after surgery will initially move towards the trachea for eventual expectoration. Later, the direction of flow is reversed with, in some cases, the appearance of radiological atelectasis. ${ }^{89}$ This directional change in mucociliary flow occurs particularly in the lung zones immediately above the operative site. The time of onset of this regional change in mucociliary flow and its duration parallel the changes in the FRC.

\section{Breathing pattern and lung mechanics}

Following abdominal surgery, breathing is restricted with shallow, rapid breaths. The shift from mainly abdominal to rib-cage breathing is due to the loss of the diaphragmatic contribution to tidal volume. ${ }^{90}$ Compliance and vital capacity are markedly reduced. The reduction in VC precedes that of FRC. ${ }^{84}$ The FRC is reduced soon, but not immediately, after upper abdominal surgery to about $70-80 \%$ of preoperative values, ${ }^{91}$ although atelectatic areas can be found immediately following surgery. ${ }^{71}$ Reduced FRC after surgery is not related to that found during anaesthesia ${ }^{84}$ Gradual restoration of lung function begins on the second or third postoperative day. Full recovery takes a few days longer, even after the resumption of gastro-intestinal function. The method of postoperative analgesia (systemic or epidural analgesia) does not alter this pattern. ${ }^{92}$

\section{Mechanism of reduced FRC and VC}

The reductions in FRC and VC are principally due to incisional pain and to reflex diaphragmatic dysfunction. Other factors include the result of shallow breathing, the absence of spontaneous sighs and the mechanical disruption of the thorax or abdomen.

Adequate pain relief by epidural analgesia, which alone has no detrimental effect on FRC, VC or gas exchange, ${ }^{93}$ brings about a small increase in $\mathrm{FRC}^{94}$ and a transient restoration of about $30 \%$ of the loss in VC. ${ }^{94.95}$ Thus, somatic pain particularly affects VC more so than FRC, and accounts for only about $30 \%$ of the reduction in VC and FRC. Reflex inhibition of diaphragmatic activity has been suspected of being a major cause of reduced FRC and $\mathrm{VC}$ and the altered breathing pattern. A number of authors have reported alterations and irregularities of breathing pattern following stimulation of splanchnic and visceral efferents. Local irritation, bowel distension and pneumoperitoneum are particularly potent inhibitors. Quantitative proof of diaphragmatic dysfunction was furnished by measuring the pressures generated during breathing. Gastric pressure (PGA) increases during breathing and is an estimate of diaphragmatic contractility. The contractility of the rib cage is measured by the decrease in Ppl. This supposes that each system acts alone. The difference (PGA-PPL) is transdiaphragmatic pressure (PDI) which takes both systems into account. During the week following operation, intrapleural pressure does not change, ${ }^{96,97}$ while PGA is maximally reduced for two days with gradual restoration over a week. ${ }^{96.97}$ The changes in maximal transdiaphragmatic pressure ( $\left.\mathrm{PDI}_{\max }\right)$ follow the same pattern as PGA (Figure 8). The volumetrically determined diaphragmatic contribution to breathing ${ }^{98}$ also follows the same pattern. These changes parallel the changes in FRC, suggesting that they are causative, presumably by reflex inhibition of the ventilatory pump due to splanchnic and peritoneal irritation. Direct stimulation of the phrenic nerves restores normal diaphragmatic movement - proof that the dysfunction is reflex. ${ }^{99}$ Epidural fentanyl ${ }^{97}$ does not affect PGA (Figure 8) in contrast to epidural bupivacaine. ${ }^{100}$ This suggests that the reflex is not due to incisional pain and that local anaesthetics may break the reflex by their sympatholytic effect. This reported difference requires confirmation and further study. Epidural morphine does not change the breathing pattern. ${ }^{101}$ The pathway for this reflex is not known and may be sympathetic or vagal.

The incidence of postoperative pulmonary complications is increased by extensive manipulation of the abdominal viscera, fluid collections, naso-gastric tubes, drains, sepsis and wound infections. These factors, presumably, further inhibit diaphragmatic contraction. An altemative explanation of the changes in PGA is the activity of abdominal wall muscles after surgery. ${ }^{102}$ There is increased abdominal muscle activity during 


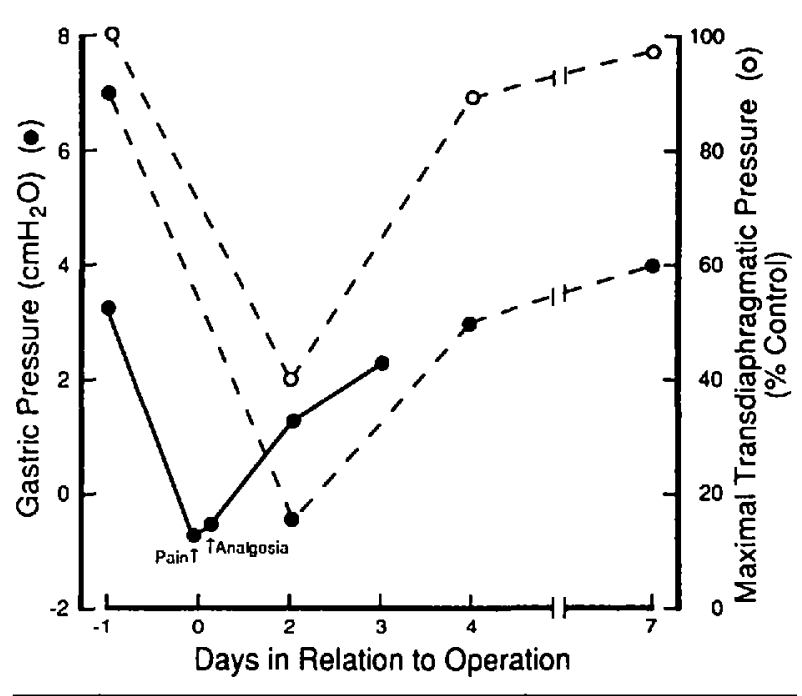

FIGURE 8 Postoperative changes in gastric and transdiaphragmatic pressure. Both pressures are reduced for two days. followed by gradual restoration. Note that epidural fentanyl administered after surgery does not change PGa. Data from reference 96 (interrupted linc) and 97 (continuous line)

expiration with abrupt cessation when inspiration starts. This expiratory activity can reduce FRC. Also, diminished diaphragmatic movements ${ }^{102}$ may result. The clinical implication of this recent observation requires further elucidation.

\section{E Postoperative atelectasis and pneumonia}

Patients who develop postoperative pulmonary complications have a relatively greater reduction of FRC, VC and $\mathrm{PaO}_{2}$ than those who do not, ${ }^{91,103}$ and have higher CC/FRC ratios. ${ }^{104}$ The restoration follows the same pattern as that noted in patients who do not develop pulmonary complications. The timing of reduced FRC suggests that preventive steps must be taken early. Active lung expansion and postoperative analgesics are two specific measures that are instituted in an attempt to prevent PPC by restoring FRC and VC.

The efficacy of deep breathing and coughing, incentive spirometry (IS) and continuous positive airway pressure (CPAP) by mask in restoring FRC and VC and preventing PPC was recently reported. The rate of restoration of FRC and of VC following abdominal surgery is the same for all three types of therapy. ${ }^{105}$ In spite of frequent sessions, the rate of restoration is not faster than usual. Three per cent of the patients in that study developed pneumonia and $35 \%$ developed radiological atelectasis. The rate of restoration following thoracotomy for cardiac operations is even slower, again without any net advantage for one form of therapy over the others. ${ }^{106}$ As would be expected, radiological atelectasis was present in the majority and most developed pleural effusions. This explains the very slow increase in FRC and VC. These two studies lead to the following two conclusions.

\section{FIRST}

Although some form of therapy is required, ${ }^{107}$ no clear advantage for one form has been demonstrated because the overall pulmonary complication (rate $22 \%$ ) was equally distributed between treatment groups. ${ }^{107}$ The intensity and frequency of sessions is more critical than the form of therapy.

\section{SECOND}

The rate of restoration of lung function is not affected by the type of therapy.

These methods of lung expansion obviously do not reverse the process. It is, therefore, quite likely that the reflex inhibition is unaffected by these lung expansion methods. The reflex inhibition may be voluntarily overridden. ${ }^{96}$

The restoration of lung function by epidural analgesia is limited. ${ }^{94.95}$ There is no difference in serial measurements of vital capacity and blood gases between epidural analgesia and parenteral morphine after abdominal cancer operations. ${ }^{108}$ The complication rate (atelectasis and pncumonia) is the same for the two methods of analgesia. ${ }^{108}$

The results following thoracic operations are different. Vital capacity and $\mathrm{PaO}_{2}$ improve more quickly with epidural morphine than with systemic morphine. ${ }^{109}$ Postoperative atelectasis and pneumonia are markedly fewer when epidural narcotics are used for post-thoracotomy analgesia. ${ }^{10,111}$ This study did not include patients who had had open heart or oesophageal surgery. The clear advantage of epidural analgesia is probably due to the lack of reflex inhibition of the diaphragm that is present after abdominal or thoracoabdominal surgery.

\section{Summary}

Postoperative pulmonary dysfunction is due to incisional pain and reflex diaphragmatic dysfunction. The restoration of FRC and VC by epidural analgesia and active lung exansion is not complete and is limited. Epidural analgesia following pulmonary surgery reduces the incidence of pneumonia.

\section{Summary and Discussion}

The FRC is reduced upon assuming the supine position and following induction of general anaesthesia. The degree of change is primarily determined by body build. The results of these sequential reductions in FRC are reduced mechanical efficiency of ventilation and an enlarged $\mathrm{P}(\mathrm{A}-\mathrm{a}) \mathrm{O}_{2}$ due to compression atelectasis, increased mismatching of ventilation:perfusion and the 
effects of airway closure. These changes are unavoidable. But the effects on oxygenation can be reduced by choosing appropriate ventilator settings and inspired $\mathrm{O}_{2}$ concentrations. There is a strong suggestion that oxygen enriched air is better than nitrous oxide:oxygen for patients with COPD. This needs confirmation. There is no definite information on whether the uptake and elimination of general anaesthetics are influenced by reduced FRC. The changes in the length (elongation) and position (anterior displacement) of the larynx are important determinants of difficult intubations. The effects of general anaesthesia on the upper airway is currently being investigated. Soon, but not immediately, after operation the FRC is reduced by an entirely different mechanism from that causing the reduction during anaesthesia. Pain (incisional and visceral) and reflex inhibition of the diaphragmatic activity cause specific changes in breathing pattern, lung mechanics, mucociliary clearance, and gas exchange. These changes are unavoidable and lead to hypoxaemia, retention of secretions, atelectasis and pneumonia if added infection occurs. Specific measures designed to counteract the effect of these changes (such as epidural analgesia and active lung expansion) do not completely reverse the changes, nor do they eliminate the incidence of postoperative atelectasis and pneumonia. The neural pathway for the reflex diaphragmatic dysfunction is not clear, is probably not a single pathway, and may involve both the autonomic and peripheral nervous systems. Identification of that pathway(s) would be very useful.

\section{Acknowledgements}

I thank Doctors J. Milic-Emili and G.S. Fox for helpful suggestions during the preparation of the text. Mrs. P. Sikender's secretarial work is greatly appreciated.

\section{References}

1 Craig DB, Wahba WM, Don HF, Couture J, Becklake MR. "Closing volume" and its relationship to gas exchange in seated and supine subjects. J. Appl Physiol 1971; 31: 717-21.

2 Muller $N$, Volgyesi $G$, Becker L, Bryan MH, Bryan $A C$. Diaphragmatic muscle tone. J Appl Physiol 1979; 47: 279-84.

3 DeTroyer A, Bastenier J, Delhez L. Function of respiratory muscles during partial curarization in humans. J Appl Physiol 1980; 49: 1049-56.

4 Briscoe WA, Dubois AB. The relationship between airway resistance, airway conductance and lung volume in subjects of different age and body size. $\mathrm{J}$ Clin Invest 1958; 37: 1279-85.
5 Behrakis PK, Baydur A, Jaeger MJ, Milic-Emili J. Lung mechanics in sitting and horizontal body positions. Chest 1983; 83: 643-6.

6 Wahba WM. The influence of aging on lung function clinical significance of changes from age twenty. Ancsth Analg 1983; 62: 764-6.

7 Don HF, Craig DB, Wahba WM, Couture JG. The measurcment of gas trapped in the lungs at functional residual capacity and the effect of posturc. Anesthesiology 1971; 35: 582-90.

8 Rehder $K$, Knopp TJ, Sessler $A D$. Regional intrapulmonary gas distribution in awake and anaesthetizedparalyzed prone man. J Appl Physiol 1979; 45: 528-38.

9 Druz WS, Sharp JT. Activity of respiratory muscles in upright and recumbent humans. J Appl Physiol 1981; 52: 1552-61.

10 Drummond GB. Chest wall movements in anaesthesia. Eur J Anaesthesiol 1989; 6: 1661-96.

11 Don $H F$, Wahba WM, Cuadrado Let al. The effects of anesthesia and 100 per cent oxygen on the functional residual capacity of the lungs. Anesthesiology 1970; 32: $521-9$.

12 Don HF, Wahba WM, Craig DB. Airway closure, gas trapping, and the functional capacity during ancsthesia. Anesthesiology 1972; 36: 533-9.

13 Hickey $R F$, Visick WD, Fairley $H B$. Fourcade $H E$. Effects of halothane anesthesia on functional residual capacity and alveolar-arterial oxygen tension difference. Anesthesiology $1973 ; 38: 20-4$.

14 Hewlett AM, Hulands $G H, N u n n J F$, Heath JR. Functional residual capacity during anaesthesia II: spontaneous respiration. Br J Anaesth 1974; 46: 486-94.

15 Hewlett AM, Hulands GH, Nunn JF, Milledge JS. Functional residual capacity during anaesthesia III: artificial ventilation. Br J Anaesth 1974; 46: 495-503.

16 Weening CP, Pietak S, Hickey RF, Farley HB. Relationship of preoperative closing volume to functional residual capacity and alveolar-artcrial oxygen tension difference during anesthesia with controlled ventilation. Anesthesiology 1974; 41: 3-7.

17 Gilmour I, Burnham M, Graig DB. Closing capacity measurement during ancsthesia. Ancsthesiology 1976; 45: 277-82.

18 Westbrooke PR, Stubbs SE, Sessler AD, Rehder K, Hyatt $R E$. Effects of anesthesia and muscle paralysis on respiratory mechanics in normal man. J Appl Physiol 1973; 34: 81-6.

19 Rehder K, Mallow JE, Fibush EE, Krabill DR, Sessler $A D$. Effects of isoflurane anesthesia and muscle paralysis on respiratory mechanics in normal man. Anesthesiology 1974; 41: 477-85.

20 Bergman NA. Reduction in resting end-expiratory position 
of the respiratory system with induction of anesthesia and neuromuscular paralysis. Anesthesiology 1982; 57: 14-7.

21 Hendenstierna G. Mc Carthy G, Bergstrom M. Airway closure during mechanical ventialtion. Anesthesiology 1976; 44: 114-23.

22 Hendenstierna G, Santesson J. Airway closure during anesthesia: a comparison between resident-gas and argon-bolus techniques. J Appl Physiol 1979; 47: 87881 .

23 Juno P, Marsh M. Knopp TJ, Rehder K. Closing capacity in awake and anaesthetized-paralyzed man. J Appl Physiol 1978; 44: 238-44.

24 Manikian B, Cantineau JP, Sartene R, Clergue F, Viars $P$. Ventilatory pattern and chest wall mechanics during ketamine anesthesia in man. Anesthesiology 1986; 65: 492-9.

25 Shulman D, Bar-Yoishay E, Beardsmore C, Godfrey $S$. Determinants of end expiratory volume during ketamine or halothane anesthesia. Anesthesiology 1987; 66: $636-40$

26 Damia $G$, Mascheroni $M$, Croci $M$, Tarenzi L. Perioperative changes in functional residual capacity in morbidly obese patients. Br J Anaesth 1988; 60: 574-8.

27 Bickler PE, Dueck R, Prutow RJ. Effects of barbiturate anesthesia on function residual capacity and rib cagc/diaphragm contributions to ventilation. Anesthesiology 1987; 66: 147-52.

28 Dueck R, Prutow RJ, Davies NJH, Clausen JL, Davidson $T M$. The lung volume at which shunting occurs with inhalation anesthesia. Ancsthesiology 1988; 69: 854-61.

29 Hedenstierna G. Strandgerg A, Brismar B, Lundquist $M D$, Svensson $L$, Tokics $L$. Functional residual capacity, thoracoabdominal dimensions, and central blood volume during general anesthesia with muscle paralysis and mechanical ventilation. Anesthesiology 1985; 62: 247-54.

30 Hedenstierna $G$, Santesson J, Norlander $O$. Airway closure and distribution of inspired gas in the extremely obese, breathing spontaneously and during anaesthesia with intermittent positive pressure ventilation. Acta Anaesthesiol Scand 1976; 20: 334-42.

31 Gold MI, Helrich $M$. Pulmonary compliance during anesthesia. Anesthesiology 1965; 26: 281-8

32 Wyche MQ, Teichner RL, Kallos T, Marshall BE, Smith $T C$. Effects of continuous positive pressure breathing on functional residual capacity and arterial oxygenation during intra-abdominal opcrations. Anesthesiology 1973; 38: 68-74.

33 Heneghan CPH, Bergman NA, Jones JG. Changes in lung volume and $\left(\mathrm{PAO}_{2}-\mathrm{PaO}_{2}\right)$ during anaesthesia. $\mathrm{Br}$ J Anacsth 1984; 56: 437-45.

34 Rehder $K$, Sittipong $R$, Sessler $A D$. The effects of thiopental-meperidine anesthesia with succinylcholine paralysis on functional residual capacity and dynamic lung compliance in normal sitting man. Anesthesiology $1972 ; 37: 395-8$.

35 Jonmarker $C$, Nordstrom $L$, Werner $O$. Changes in functional residual capacity during cardiac surgery. $\mathrm{Br}$ J Anaesth 1986; 58: 428-32.

36 Dueck R, Young I, Clausen J, Wagner PD. Altered distribution of pulmonary ventilation and blood flow following induction of inhalation anesthesia. Anesthesiology $1980 ; 52: 113-25$.

37 Hedenstierna $G$, Lundh $R$, Johansson $H$. Alvcolar stability during anesthesia for reconstructive vascular surgery of the leg. Acta Anaesthesiol Scand 1983;27: 26-34.

38 Lundh $R$, Hedenstierna $G$, Strandberg $A$ et al. Ventilation-perfusion relationships during anesthesia and abdominal surgery. Acta Anaesthesiol Scand 1983; 27: 167-73.

39 Drummond $G B$. Reduction of tonic rib cage muscle activity by anesthesia with thiopental. Anesthesiology 1987; 67; 695-700.

40 Germain $M$, Wahba WM, Gillies DMMG. Ventilation following induction of general anacsthesia by thiopentone. Can Anaesth Soc J 1982; 29: 100-4.

41 Froese $A B$, Bryan $A C$. Effects of anesthesia and paralysis on diaphragmatic mechanics in man. Anesthesiology 1974; 41: 242-55.

42 Krayer $S$, Rehder $K$, Vettermann J, Didier EP, Ritman $E$. Postition and motion of the human diaphragm during anesthesia paralysis. Anesthesiology 1989; 70: 891-8.

43 Logan MR, Allan PL, Drummond GB. Changes in diaphragmatic postition in association with the induction of anaesthesia. Br J Anaesth 1986; 58: 1246-51.

44 Vellody VPS, Nassery $M$, Balasaraswathi $K$, Goldberg $N B$, Sharp JT. Compliances of the human rib cage and diaphragm-abdomen pathways in the relaxed versus paralyzed states. Am Rev Respir Dis 1978; 118 : 479-91.

45 Krayer S, Rehder K, Beck KC, Cameron PD, Didier EP, Hoffman EA. Quantification of thoracic volumes by three-dimensional imaging. J Appl Physiol 1987; 62: 591-8.

46 Hedenstierna $G$, Lofstrom $D$, Lundh $R$. Thoracic gas volume and chest-abdomen dimensions during ancsthesia and muscle paralysis. Anesthesiology 1981; 55: 499-506.

47 Logan MR, Brown DT, Newton I, Drummond GB. Stereophotogrammetric analysis of changes in body volume associated with the induction of anaesthesia. $\mathrm{Br} \mathrm{J}$ Anaesth 1987; 59: 288-94. 
48 Drummond $G B$, Park $G R$. Changes in intragastric pressure on induction of anaesthesia. Br J Anaesth 1984; 56: 873-9.

49 Froese $A B$. Anesthesia-paralysis and the diaphragm: in pursuit of an elusive muscle (Editorial). Ancsthesiology 1989; 70: 887-90.

50 De Troyer A, Sampson M, Sigrist S, Macklem PT. The diaphragm: two muscles. Science 1981; 213: 237-8.

51 Kaul SU, Heath JR, Nunn JF. Factors influencing the development of expiratory muscle activity during anaesthesia. Br J Anaesth 1973; 45: 1013-8.

52 Freund $F$, Roos $A$, Dodd RB. Expiratory activity of the abdominal muscles in a man during general anesthesia. J Appl Physiol 1964; 19: 693-7.

53 Jones $J G$, Faithfull $D$, Jordan $C$, Minty $B$. Rib cage movement during halothane anaesthesia in man. $\mathrm{Br} \mathrm{J}$ Anacsth 1979; 51: 399-407.

54 Hedenstierna $G$, Johansson $H$, Linde $B$. Central blood volume as an explanation for lowered FRC during anesthesia? Thigh volume measurements by plethysmography. Acta Anaesthesiol Scand 1982; 26: 633-7.

55 Drummond GB, Pye DW, Annan FJ, Tothill $P$. Changes in blood volume distribution associated with general anaesthesia. $\mathrm{Br} J$ Anaesth 1988; 60; 331P.

56 Gal TJ, Surratt $P M$. Resistance to breathing in healthy subjects following endotracheal intubation under topical anesthesia. Anesth Analg 1980; 59: 270-4.

57 Waltmath CL, Bergman NA. Respiratory compliance in obcsc patients. Ancsthesiology 1974; 41: 84-5.

58 Beydour A, Sassoon CSH, Stiles CM. Partitioning of respiratory mechanics in young adults. Effects of duration of anesthesia. Am Rev Respir Dis 1987; 135: 165-72.

59 Behrakis PK, Higgs BD, Bevan DR, Milic-Emili J. Partitioning of respiratory mechanics in halothaneanesthetized humans. J Appl Physiol 1985; 58: 285-9.

60 Behrakis PK, Higgs BD, Baydour A, Zin WA, Milic-Emili $J$. Repiratory mechanics during halothane anesthesia and ancsthesia-paralysis in humans. J Appl Physiol 1983; 55: 1085-92.

61 Hendenstierna G, McCarthy G. Mcchanics of breathing, gas distribution and functional residual capacity at different frequencies of respiration during spontancous and artificial ventilation. Br J Anaesth 1975; 47: 706-12.

62 Lehane JR. Jordan J, Jones JG. Influcnce of halothane and enflurane on respiratory airflow resistance and specific conductance in anaesthetized man. $\mathrm{Br} \mathrm{J}$ Anacsth 1980; 52: 773-80.

63 Pietak S, Weenig CS, Hickey RF, Fairley HB. Ancsthetic effects on ventilation in patients with chronic obstructive pulmonary disease. Anesthesiology 1975; 42: 160-6

64 Wahba WM. Influence of airway resistance and ventila- tory pattem on $\mathrm{PaCO}_{2}$ during enflurane anacsthesia. $\mathrm{Br} \mathrm{J}$ Anaesth $1979 ; 51: 123-6$.

65 Sivarajan $M$, Fink $B R$. The position and the state of the larynx during general anesthesia and muscle paralysis. Ancsthesiology 1990; 72: 439-42.

66 Frumin MJ, Bergman NA, Holaday DA et al. Alveolararterial $\mathrm{O}_{2}$ differences during artificial respiration in man. J Appl Physiol 1959; 14: 694-700.

67 Bendixen $H H$, Hedley-Whyle J, Laver $M B$. Impaired oxygenation in surgical patients during general anesthesia with controlled ventilation: a concept of atelectasis. N Engl J Mcd 1963; 269: 991-6.

68 Panday $J$, Nunn JF. Failure to demonstrate progressive falls of arterial $\mathrm{PO}_{2}$ during anaesthesia. Anaesthesia 1968; 23: 38-46.

69 Brismar B, Hedenstierna $G$, Linquist $H$, Strandberg $A$, Svensson $L$, Tokics $L$. Pulmonary densities during anesthesia with musclular relaxation - a proposal of atelectasis. Anesthesiology 1985; 672: 422-8.

70 Gunnarsson L, Strandberg A, Brismar B, Tokics $L$ Lundquist $H$, Hedenstierna $G$. Atelectasis and gas exchange impairment during enfluane/nitrous oxide anaesthesia. Acta Anaesthesiol Scand 1989; 33: 62937.

71 Strandberg A, Tokics $L$, Brismar B, Lundquist $H$, Hedenstierna $G$. Atclectasis during anaesthesia and in the postoperative period. Acta Anaesthesiol Scand 1986; 30: $154-8$.

72 Strandberg A, Hedenstierna $G$, Tokics L. Lundquist $H$, $B$ rismar $B$. Densities in dependent lung regions during anaesthesia: atelectasis or fluid accumulation? Acta Anaesthesiol Scand 1986; 30: 256-9.

73 Hedenstierna $G$, Tokics $L$. Strandberg $H$, Lundquist $H$, Brismar $B$. Correlation of gas cxchange impairment to development of atelectasis during anaesthesia and muscle paralysis. Acta Anaesthesiol Scand 1986; 30: 183-91.

74 Tokics L, Hedenstierna G, Strandberg A, Brismar BO, Lundquist $H$. Lung collapse and gas exchange during general anesthesia: effects of spontaneous breathing. muscle paralysis and positive end-expiratory pressure. Anesthesiology 1987; 66: 157-67.

75 Tokics L, Strandberg A, Brismar B, Lunquist H, Hedenstierna $G$. Computerized tomography of the chest and gas exchange measurements during kctamine anaesthesia. Acta Anaesthesiol Scand 1987; 31: 684-92.

76 Gunnarsson L, Tokics L, Lundquist $H$ et al. Chronic obstructive pulmonary discase and anaesthesia formation of atelectasis and gas cxchange impairment. Acta Anaesthesiol Scand (In press).

77 Standberg A, Tokics L, Brismar B, Lundquist $H$, Hedenstierna $G$. Constitutional factors promoting development of atelectasis during anaesthesia. Acta Anaesthesiol Scand 1987; 31: 21-4. 
78 Bergman NA, Tien YK. Contributions of the closure of pulmonary units to impaired oxygenation during anesthesia. Anesthesiology 1983; 59: 395-401.

79 Forkent L, Dhinger B, Anthonisen NR. Airway closure and closing volume. J Appl Physiol 1979; 42: 391-402.

80 Nunn JF, Williams IP, Jones JG et al. Detcction and reversal of pulmonary absorption collapse. $\mathrm{Br} \mathbf{J}$ Anaesth 1978; 50: 91-100.

81 Binslev L, Hedenstierna G, Santisson J, Norlander $O$, Gram I. Airway closure during anacsthesia and its prevention by positive end expiratory pressure. Acta Anacsthesiol Scand 1980; 24: 199-205.

82 Visick WD, Fairley $H B$, Hickey $R F$. The effects of tidal volume and end expiratory pressure on pulmonary gas exchange during anesthesia. Anesthesiology 1973; 39: 285-90.

83 Fletcher $R$. Gas cxchange during thoracotomy in children. A study using the single-breath test for $\mathrm{CO}_{2}$ Acta Anaesthesiol Scand 1987; 31: 391-6.

84 Craig $D B$. Postoperative recovery of pulmonary function. Anesth Analg 1981; 60: 46-52.

85 Kitamura H, Sawa T, Ikezomo E. Postoperative hypoxemia: the contribution of age to the maldistribution of ventilation. Anesthesiology 1972; 36: 244-52.

86 Vaughan RW, Engelhardt RC, Wise L. Postoperative hypoxemia in obese patients. Ann Surg 1974; 180: 877-82.

87 Alexander JI, Spence AA, Parikh RK et al. The role of airway closure in postoperative hypoxaemia. $\mathrm{Br} \mathrm{J}$ Anaesth 1973; 45: 34-40.

88 Catley DM, Thornton C, Jordan Cet al. Pronounced, episodic oxygen desaturation in the postoperative period: its association with ventilatory pattern and analgesic regimen. Anesthesiology 1985; 63: 20-8.

89 Gamsu G, Singer MM, Vincent HH, Berry S, Nadel $J A$. Postoperative impairment of mucus transport in the lung. Am Rev Respir Dis 1976; 114: 673-9.

90 Tahir AA, George RB, Weill H, Adriani J. Effects of abdominal surgery upon diaphragmatic function and regional ventilation. Am Rev Respir Dis 1983; 127 : 431-6.

91 Ali J, Weisel RD, Layug AB, Kripke BJ, Hechtman $H B$. Consequences of postoperative alterations in repiratory mechanics. Am J Surg 1974; 128: 376-82.

92 Bonnet $F$, Blery $C H$, Zatan $O$, Brage D, Gaudy JH. Effect of epidural morphine on postoperative pulmonary dysfunction. Acta Arasthesiol Scand 1984; 28: 147-51.

93 Wahba $M W$, Craig DB, Don HF, Becklake MR. The cardiorespiratory effects of thoracic epidural anaesthesia. Can Anaesth Soc J 1972; 19: 8-19.

94 Wahba MW, Don HF, Craig DB. Postoperative epidur- al analgesia: effects on lung volumes. Can Anaesth Soc J 1975; 22: 519-27.

95 Benhamou D, Samii $K$, Noviant $Y$. Effect of analgesia on respiratory muscle function after upper abdominal surgery. Acta Anaesthesiol Scand 1983; 27: 22-5.

96 Ford GT, Whitelaw WA, Rosenal TW, Cruse PJ, Guenther $C A$. Diaphragm function after upper abdominal surgery in humans. Am Rev Respir Dis 1983; 127: 431-6.

97 Simonneau $G$. Vivien A, Sartene $R$ et al. Diaphragmatic dysfunction induced by upper abdominal surgery. Rolc of postoperative pain. Am Rev Respir Dis 1983; 128 : 899-903.

98 Dureuil B, Canrineau JP, Desmonts JM. Effects of upper or lower abdominal surgery on diaphragm function. $\mathrm{Br}$ J Anacsth 1987; 59: 1230-5.

99 Dureuil B, Viires N, Cantineau JP, Augier M, Desmonts $J M$. Diaphragmatic contractility after upper abdominal surgery. J Appl Physiol 1986; 49; 1775-80.

100 Mankikian $B$, Cantineau JP, Bertrand $M$ et al. Improvement of diaphragmatic function by a thoracic extradural block after upper abdominal surgery. Anesthesiology 1988; 68: 379-86.

101 Clergue $F$, Montembault $C$, Despierres $O$, Ghesquiere $F$. Harari $A$, Viars $P$. Respiratory effects of intrathecal morphine after upper abdominal surgery. Anesthesiology 1984; 61: 677-85.

102 Duggan JE, Drummond GB. Abdominal muscle activity and intraabdominal pressure after upper abdominal surgery. Anesth Analg 1989; 69: 598-603.

103 Meyers JR, Lembeck L, O'Kane H, Bauer $A E$. Changes in functional residual capacity of the lung after operation. Arch Surg 1975; 110: 576-83.

104 Wiren JE, Janzon L. Respiratory complications following surgery. Improved prediction with prcoperative spirometry. Acta Anaesthesiol Scand 1983; 27: 476-9.

105 Stock MC, Downs JB, Gauer PK el al. Prevention of postoperative pulmonary complication with CPAP, incentive spirometry and conservative therapy. Chest 1985; 87: 151-7.

106 Stock MC, Downs JB, Cooper RB et al. Comparison of continuous positive airway pressure, incentive spirometry and conservative therapy after cardiac operation. Crit Care Med 1984; 12: 969-72.

107 Celli BR, Rodriguez KS, Snider GL. A controlled trial of intermittent positive pressure breathing, incentive spirometry and deep breathing excrcises in preventing pulmonary complications after abdominal surgery. Am Rev Respir Dis 1984; 130: 12-5.

108 Jayr C, Mollie A, Bourgain JL et al. Postoperative pulmonry complications: general anesthesia with postoperative parenteral morphine compared with epidural analgesia. Surgery 1988; 104: 57-63. 
109 Shulman MS, Sandler AN, Bradley JW, Young PS,

Brebner J. Postthoracotomy pain and pulmonary function following cpidural and systemic morphine. Anesthesiology 1984; 61: 569-75.

110 Hasenbos $M$, van Egmond J, Gielen M, Crul JF. Postoperative analgesia by epidural versus intramuscular nicomorphine after thoracotomy. Part II. Acta Anaesthesiol Scand 1985; 29: 577-82.

111 Hasenbos $M$, van Egmond J, Gielen M, Crul JF. Postopcrative analgesia by high thoracic epidural versus intramuscular nicomorphine after thoracotomy. Part III. Acta Anaesthesiol Scand 1987; 31: 608-15. 